Hoffman makes a convincing case that knowledgeable bystanders are most likely to save the lives of some unconscious casualties at the site of the accident both by correct positioning and by preventing obstruction of the upper airway or to inhalation. The voluntary organisations, such as the St John Ambulance Brigade and the Red Cross, have had a long established role in training the public in first aid, both with full first aid courses leading to the issue of a certificate and with two hour courses in emergency aid concentrating on cardiopulmonary resuscitation. A more recent development by the St John Ambulance Brigade has been teaching first aid to schoolchildren attending Butlin's Youth Adventure Weeks, no fewer than 28000 children being given tuition in a single year. Baskett confirmed this, especially the crucial part that the public can play if cardiopulmonary resuscitation is to realise its full lifesaving potential-a principle supported by Sloman, who, describing an integrated paramedic service and hospital support in Melbourne, Australia, found that help from the bystanders was essential for success. Of 85 patients given cardiopulmonary resuscitation by members of the public, 22 survived to leave hospital; but of 83 who were not given such resuscitation, none survived to leave hospital.

In the Middlesbrough survey Hoffman found that bystanders gave first aid in four fifths of the cases and the police in a quarter before the ambulance arrived. (Police are, of course, taught first aid during their basic training and in refresher courses.) Ambulance men were usually the first to give expert aid and carried out their duties effectively, particularly in towns such as Brighton, which has introduced advanced training for them. ${ }^{7}$ Nevertheless, some are opposed to specialised training programmes that will of necessity lead to a two tier ambulance service, and this attitude has also been reflected in the St John Ambulance Brigade, though the attitude in their recent Public Duty Handbook may well herald a change of heart. ${ }^{8}$

The important educational role of the media should not be forgotten. In the United States public interest in resuscitation was aroused by television programmes featuring the emergency treatment of heart attacks, and some 20 million people attended classes on cardiopulmonary resuscitation. ${ }^{9}$ In Britain recent motoring magazine programmes have shown useful items on first aid, notably BBC2's Top Gear, and it seems likely that this will further kindle interest in first aid in this country. Another stimulus is likely to be the recently established Community Resuscitation Council set up by the professional organisations engaged in the treatment of medical and surgical emergencies. As Hoffman points out, in any road accident the first person on the scene is likely to be other drivers, and these should be singled out for training. The inclusion of a section on first aid in the latest edition of the Highway Code ${ }^{10}$ in Britain is a welcome addition, but questions on this topic should be included when taking a driving test. In some countries-for example, West Germany and Australia - an examination in first aid is already obligatory for obtaining a driving licence.

In Norway instruction in resuscitation in schools has been compulsory since 1961. In Britain, on the other hand, road safety and first aid are not in the curriculum, and the decision to include them lies with local education authorities and individual schools. Yet the Butlin's experience by the St John Ambulance Brigade would appear to show that, given the chance, many children would elect to learn these skills. Certainly the cadet movements of both the Red Cross and the St John Ambulance Brigade, together with the scouting and guide movements, have brought first aid instruction to tens of thousands of children. Nevertheless, pressure from the Department of Education to teach these subjects in all schools would undoubtedly be beneficial and might whet the appetite of many to join the voluntary organisations and learn more.

BRIAN LEWIS

Consultant Anaesthetist,

Hythe,

Kent CT21 4BD

${ }^{1}$ Hoffman E. Road accidents: resuscitation on site. Injury 1982;14:245-9.

2 Spelman JW, Bordner KR, Howard JM. Traffic fatalities in Philadelphia. f Trauma 1970;10:885-9.

${ }^{3}$ Gögler E. Di schweren Autobahnunfälle. Helv Chir Acta 1972;39:53-8.

4 Easton KC. The general practitioner and the rural accident services. Injury $1972 ; 3: 274-7$.

5 Baskett PJF. The need to disseminate knowledge of resuscitation into the community. Anaesthesia $1982 ; 37: 74-6$.

- Zorab J, Baskett P. Mobile resuscitation units. Br Medf 1976;i:650.

7 Mackintosh AF, Crabb ME, Grainger R, Williams JH, Chamberlain DA. The Brighton resuscitation ambulances: review of 40 consecutive survivors of out-of-hospital cardiac arrest. Br Med F 1978;i:115-8.

${ }^{8}$ St John Ambulance Brigade. Public duty handbook. London: St John Ambulance Brigade, 1983.

${ }^{9}$ Laerdal AS. Our brothers' distress. In: Baskett PJF, ed. Immediate prehospital care. New York: John Wiley, 1981:1.

${ }^{10}$ Department of Transport and Central Office of Information. The highway code. London: HMSO, 1982.

\section{Congenital complete heart block}

When complete atrioventricular dissociation with a slow ventricular rate is known to have been present from an early age the diagnosis made is congenital complete heart block. ${ }^{1}$ Postinfective or postsurgical causes should have been excluded. The condition is much rarer than acquired heart block, with an incidence of one in 15000 to 20000 live births, ${ }^{23}$ and it accounts for one in 200 referrals to paediatric cardiology centres. ${ }^{4}$ Congenital complete heart block is associated with other congenital heart disease in up to one third of cases, ${ }^{2}$ particularly (corrected) L transposition of the great arteries. ${ }^{5}$

In isolated congenital heart block the usual histological findings are fibrosis in the atrial septum above the atrioventricular node or interruption of the bundle of His or its branches. ${ }^{6}$ The functional site of block, determined clinically by His bundle electrocardiography, is proximal to the bundle in two thirds or more of recordings. ${ }^{7} 8$

Considerable interest has been shown in the association between isolated congenital heart block and disease of the maternal connective tissue, particularly systemic lupus erythematosus. In a multicentre survey of 425 cases of congenital heart block Esscher ${ }^{9}$ found 64 mothers with active or latent lupus erythematosus, rheumatoid arthritis, connective tissue diseases, or abnormalities on serological testing. In a recent study presented to the British Cardiac Society the IgG antibody anti-Ro(SSA) was present transiently in the serum of neonates with congenital heart block and in many of their mothers. ${ }^{10}$ It seems likely that anti-Ro or some other maternal IgG antibody crossing the placenta is an aetiological agent in many cases of congenital heart block.

Congenital heart block may be diagnosed in utero, in the neonatal period, in childhood, or rarely in adult life. The prognosis appears to be worse when the clinical presentation is in the neonatal period. Of 118 patients diagnosed shortly after birth, 29 had signs of cardiac failure and 15 died. ${ }^{9}$ In another series the overall mortality was $12 \%$ at 6 months but 
had increased to only $15 \%$ at 20 years. As would be expected, mortality is higher in infants with coexisting congenital heart disease than in those with isolated heart block. ${ }^{5}$ The causes of death are Stokes-Adams attacks or congestive cardiac failure.

Nevertheless, the asymptomatic infant with heart block still has a guarded prognosis even after the first year of life. In Esscher's series there was a $6 \%$ mortality between the ages of 6 months and 15 years and $18 \%$ of her patients required pacemakers because of syncopal attacks or heart failure. ${ }^{9}$ As patients reach adult life an increasing number develop symptoms and require pacemakers. ${ }^{311}$ The management of congenital complete heart block has improved enormously with the advent of small longlasting pacemaker generators-but there are still considerable technical problems in permanent pacing in small children. ${ }^{12}$ Pacing is mandatory in the presence of Stokes-Adams attacks or heart failure and may improve exercise tolerance if this is limited by a slow heart rate. Many patients with congenital heart block, however, can increase their ventricular rate satisfactorily on exercise and so remain asymptomatic. Can we identify which of them is at risk of sudden death?

Most authors suggest that the likelihood of symptoms is inversely related to the ventricular rate. All the patients who died in the neonatal period in one study had a rate below 60 a minute, ${ }^{9}$ and the mean ventricular rate in other series was lower in patients with symptoms than those without, in both childhood and adult life. ${ }^{71}$ Ambulatory electrocardiographic monitoring has shown episodes of profound ventricular slowing at night, ${ }^{8}$ though the prognostic relevance of this is unknown. Location of the site of the block by intracardiac recording was of no help in predicting the risk of syncope, though block in or distal to the bundle of His was associated with a slower ventricular rate than proximal block. ${ }^{7}$

Molthan et $a l^{13}$ described three deaths in patients with widening of the QRS complex and QT interval; two had episodes of ventricular tachycardia or fibrillation as well as ventricular standstill. Esscher ${ }^{9}$ observed a corrected QT interval of over 0.44 second in $84 \%$ of patients with symptoms. Patients with congenital heart block have a higher incidence of ventricular ectopic activity on exercise than controls, the incidence being particularly high in those with QRS widening. ${ }^{14}$ These results raise the possibility that some of the sudden deaths in patients with congenital heart block arise from ventricular tachyarrhythmias rather than asystole.

At present, then, permanent pacing is indicated for patients with congenital complete heart block if they have episodes of syncope, dizziness, heart failure, or impaired effort tolerance. The remainder need careful lifelong follow up. Future studies may show the need for prophylactic pacing in asymptomatic patients with a slow ventricular rate or a prolonged QRS or $\mathrm{QT}_{\mathrm{c}}$ interval.

S M COBBE

Clinical Reader and Honorary Consultant Cardiologist,

Cardiac Department,

John Radcliffe Hospital,

Oxford OX43 9DU

${ }^{1}$ Yater WM. Congenital heart-block-review of the literature; report of a case with incomplete heterotaxy; the electrocardiogram in dextrocardia. Am $\mathcal{F}$ Dis Child 1929;38:112-36.

${ }^{2}$ Michäelsson M, Engle MA. Congenital complete heart block: an international study of the natural history. Cardiovasc Clin 1972;4:85-101.

${ }^{3}$ Reid JM, Coleman EN, Doig W. Complete congenital heart block. Report of 35 cases. Br Heart $\mathcal{F} 1982 ; 48: 236-9$.

${ }^{4}$ Keith JD, Rowe RD, Vlad P. Heart disease in infancy and childhood. 3rd ed. New York: Macmillan, 1978:290-2.

${ }^{5}$ Pinsky WP, Gillette PC, Carson A Jr, McNamara DG. Diagnosis, management, and long-term results of patients with congenital complete atrioventricular block. Pediatrics 1982;69:728-33.
${ }^{6}$ Lev M. Pathogenesis of congenital atrioventricular block. Prog Cardiovdso Dis $1972 ; 15: 145-58$.

${ }^{7}$ Karpawich PP, Gillette PC, Garson A Jr, Hesslein PS, Porter CMcNamara DG. Congenital complete atrioventricular block: clinica and electrophysiologic predictors of need for pacemaker insertion. Am f Cardiol 1981 ;48:1098-102.

${ }^{8}$ Levy AM, Camm AJ, Keane JF. Multiple arrhythmias detected durim nocturnal monitoring in patients with congenital complete heart block Circulation 1977;55:247-53.

${ }^{9}$ Esscher E. Congenital complete heart block. Acta Paediatr Scand $198 \%$. 70:131-6. (Review article.)

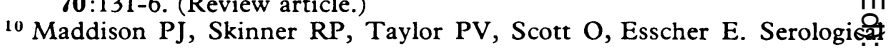
studies in congenital heart block. Br Heart $\mathcal{f}$ (in press). (Abstract.)

11 Esscher EB. Congenital complete heart block in adolescence and adult life A follow-up study. Eur Heart $\mathcal{F} 1981 ; 2: 281-8$.

12 Hayward R, Somerville J, Rickards AF. Problems of permanent pace. making in children. PACE 1979;2:A872.

${ }^{13}$ Molthan ME, Miller RA, Hastreiter AR, Paul MH. Congenital heaf block with fatal Adams-Stokes attacks in childhood. Pediatrics 196\$; 30:32-41.

14 Winkler RB, Freed MD, Nadas AS. Exercise-induced ventricular ectopy in children and young adults with complete heart block. Am Heart -7 $1980 ; 99: 87-92$.

\section{The sticky eyed infant}

A sticky eyed infant will worry his parents and should concerin his doctor-for prompt and appropriate treatment is called fow

Conjunctivitis in the neonate presents with redness, dis charge, and sometimes watering; the condition is known ophthalmia neonatorum and was once a major cause of neonaty blindness in the West. ${ }^{1}$ The severe corneal damage caused infection with Neisseria gonorrhoeae led to the use of the Credé prophylaxis with silver nitrate drops, and this reduced the rage of ophthalmia neonatorum in infants born to infected motheig to less than $2 \%{ }^{2}$ For many years now most European countries and much of the United States of America, however, haze abandoned the use of routine prophylaxis, because of the occurrence of chemical conjunctivitis from the silver nitrage drops themselves and the introduction of reliable diagnostif facilities. ${ }^{3}$

Nevertheless, ophthalmia neonatorum remains common Culture of the discharge may allow a specific diagnosis to made. $N$ gonorrhoeae, Staphylococcus aureus, Streptococc viridans, and Haemophilus spp are established bacterial path gens, but in recent years Chlamydia trachomatis is being detect more frequently ${ }^{4}$ and accounts for many of the infections re sistant to chloramphenicol. Material from a conjunctival swa should be examined with a Gram stain and cultured for both bacterial and viral pathogens in all severe cases, all those whe the mother is known to be infected, in the presence of ard corneal damage, or in infants who have not responded to treats ment. Probably the most effective antibiotic to use initially $\underline{\underline{T}}$ $1 \%$ chloramphenicol ointment given six times daily; in patieng shown to have infection with chlamydia tetracycline ointme may be given to the baby ${ }^{5}$ while his mother is treated wi erythromycin.

The second common cause of a watering eye in a baby obstruction of the nasolacrimal duct, which occurs in nearty half of all newborn babies but causes symptoms in very few The affected eye waters, especially in the cold or wind, and $\stackrel{0}{\Phi}$ prone to infections, often by organisms of low pathogenicit\$. Sometimes a mucocele of the lacrimal sac develops or may present at birth ${ }^{7}$; it may be detected by firm but gentle pressufe medial to and below the inner canthus, which will express mucus or pus into the conjunctival sac. The obstruction to the nasolacrimal system is usually at the lower end of the nas lacrimal duct and is a result of incomplete development. ${ }^{8}$ 